Article

\title{
Assessment of the Suomi NPP VIIRS Land Surface Albedo Data Using Station Measurements and High-Resolution Albedo Maps
}

\author{
Yuan Zhou ${ }^{1, *}$, Dongdong Wang ${ }^{1}$, Shunlin Liang ${ }^{1,2}$, Yunyue $\mathrm{Yu}^{3}$ and Tao He ${ }^{1}$ \\ 1 Department of Geographical Sciences, University of Maryland, College Park, MD 20742, USA; \\ ddwang@umd.edu (D.W.); sliang@umd.edu (S.L.); taohers@gmail.com (T.H.) \\ 2 State Key Laboratory of Remote Sensing Science, School of Geography, Beijing Normal University, \\ Beijing 100875, China \\ 3 Center for Satellite Applications and Research, National Environmental Satellite, Data, \\ and Information Service, National Oceanic and Atmospheric Administration, College Park, MD 20740, USA; \\ yunyue.yu@noaa.gov \\ * Correspondence: yzhou128@umd.edu; Tel.: +1-301-547-5228
}

Academic Editors: Richard Müller and Prasad S. Thenkabail

Received: 6 December 2015; Accepted: 26 January 2016; Published: 8 February 2016

\begin{abstract}
Land surface albedo (LSA), one of the Visible Infrared Imaging Radiometer Suite (VIIRS) environmental data records (EDRs), is a fundamental component for linking the land surface and the climate system by regulating shortwave energy exchange between the land and the atmosphere. Currently, the improved bright pixel sub-algorithm (BPSA) is a unique algorithm employed by VIIRS to routinely generate LSA EDR from VIIRS top-of-atmosphere (TOA) observations. As a product validation procedure, LSA EDR reached validated (V1 stage) maturity in December 2014. This study summarizes recent progress in algorithm refinement, and presents comprehensive validation and evaluation results of VIIRS LSA by using extensive field measurements, Moderate Resolution Imaging Spectroradiometer (MODIS) albedo product, and Landsat-retrieved albedo maps. Results indicate that: (1) by testing the updated desert-specific look-up-table (LUT) that uses a stricter standard to select the training data specific for desert aerosol type in our local environment, it is found that the VIIRS LSA retrieval accuracy is improved over a desert surface and the absolute root mean square error (RMSE) is reduced from 0.036 to 0.023 , suggesting the potential of the updated desert LUT to the improve the VIIRS LSA product accuracy; (2) LSA retrieval on snow-covered surfaces is more accurate if the newly developed snow-specific LUT (RMSE $=0.082$ ) replaces the generic LUT (RMSE $=0.093$ ) that is employed in the current operational LSA EDR production; (3) VIIRS LSA is also comparable to high-resolution Landsat albedo retrieval (RMSE $<0.04$ ), although Landsat albedo has a slightly higher accuracy, probably owing to higher spatial resolution with less impacts of mixed pixel; (4) VIIRS LSA retrievals agree well with the MODIS albedo product over various land surface types, with overall RMSE of lower than 0.05 and the overall bias as low as 0.025 , demonstrating the comparable data quality between VIIRS and the MODIS LSA product.
\end{abstract}

Keywords: albedo; Suomi NPP; VIIRS; Landsat; accuracy assessment

\section{Introduction}

Land surface albedo (LSA), defined as the ratio between solar radiation reflected by Earth's land surface and solar radiation incident at the surface, is a function of both solar illumination and the reflective properties of land [1]. LSA directly affects Earth's climate by determining the fraction of shortwave radiation absorbed at the ground, and therefore, it influences the surface 
energy budget [2]. It is a fundamental component in determining the magnitude of energy fluxes in the soil-plant-atmosphere continuum [3,4], affecting the surface temperature, evaporation and transpiration, cloud formation, and precipitation, thus ultimately impacting the gross primary productivity [2,5-8]. Surface albedo is also a key factor in the potential positive feedback between surface temperature and global warming at northern latitudes [9] and may play a relevant role in offsetting the carbon sequestration potential of afforestation programs [10-13]. Among the model applications, LSA is a parameter needed by both global and regional climatic models and for computing the surface energy balance $[9,14]$. The seasonal and long-term vegetation dynamics that significantly impact the climate are reflected by the dramatic variations of albedo [14]. Thus, long-term observation and retrieval of LSA are an irreplaceable resource for monitoring the variability of LSA and understanding its interaction with the climate system [15].

Remote sensing technique provides a unique opportunity to efficiently and frequently map global LSA. Dating back to the year 1973, the meteorological satellite Nimbus 3 [16] opens the first attempt to generate a global LSA map. From then on, a series of optical sensors have been employed to retrieve global data on LSA $[17,18]$. However, no global LSA products had been operationally produced until the Moderate Resolution Imaging Spectroradiometer (MODIS), one of the sensors in the National Aeronautics and Space Administration (NASA) Earth Observing System (EOS) Terra and Aqua platform, launched in 1999 and 2002, respectively [19-21]. MODIS provides comprehensive and frequent global Earth imaging in 36 spectral bands and at high spatial resolutions $(500 \mathrm{~m}, 1 \mathrm{~km})$ and better spectral configuration, facilitating a high-quality global albedo product at an eight-day frequency [19]. In the past decade, extensive studies have been conducted, leading to the development of robust algorithms to retrieve surface albedo using MODIS data [19,22-28]; moreover, comprehensive validations on MODIS albedo products have also been performed $[8,27,29]$. In addition to MODIS, many other albedo products with various spatial resolutions and temporal frequencies are also generated and validated, such as polarization and directionality of the Earth's reflectance (POLDER) [30-32], Medium Resolution Imaging Spectrometer (MERIS) [33], Clouds and the Earth's Radiant Energy System (CERES) (Bias $=-0.004$, RMS $=0.02$ over land sites) [34,35], and Airborne Visible Infrared Imaging Spectrometer (AVIRIS) (RMSE < 0.034) [36].

As the successor of MODIS, the Visible Infrared Imaging Radiometer Suite (VIIRS) from the Suomi National Polar-orbiting Partnership (S-NPP) and future Joint Polar Satellite System (JPSS) will lead us into a new era of global daily earth observations, furnishing us with a continuous opportunity to monitor LSA both regionally and globally. VIIRS was designed to improve the capabilities of the operational Advanced Very High Resolution Radiometer (AVHRR) and provide observation continuity with MODIS [37]. LSA is a globally operational product in the form of a VIIRS environmental data record (EDR) since the beginning of 2012, with a moderate spatial resolution of $750 \mathrm{~m}$ at nadir during the satellite over-pass time (local 13:30). Currently, the improved bright pixel sub-algorithm (BPSA) method is a unique algorithm that is employed by VIIRS to routinely generate LSA EDR from VIIRS top-of-atmosphere (TOA) observations. Proposed in [15], this method links the surface broadband albedo with the observed reflectance at TOA. Preliminary validations were conducted in our earlier works by comparing the VIIRS LSA retrieval with the field albedo measurements over seven SURFRAD sites and with MODIS albedo product [15]. Furthermore, in the JPSS quality control (QC) procedure that includes a series of maturity status review processes (i.e., beta, provisional validated V1, validated V2, and validated V3 stages), the VIIRS LSA EDR product had completed the validated V1 stage maturity review in December 2014. The V1 stage is a critical milestone in the JPSS EDR production; it is defined as "using a limited set of samples, the algorithm output is shown to meet the threshold performance attributes identified in the JPSS level 1 requirements." It has been over three years since VIIRS LSA EDR started its operation in 2012, leading to the collection of sufficient data to perform further validation and evaluation of the quality and accuracy of this product. Therefore, this paper summarizes recent progress made in algorithm refinement, and presents comprehensive validation results of LSA EDR. Compared to the preliminary validation in [15] which reported validation accuracy 
over seven Surfrad sites $($ RMSE $=0.049$, Bias $=-0.004)$, this study includes more ground measurement sites to obtain a more reliable assessment of the retrieval algorithm, aiming at pushing steps forward to achieve the final accuracy objective of VIIRS LSA EDR product (RMSE $\leqslant 0.02$, Bias $\leqslant 0.0125$ ). Moreover, intercomparisons are also performed among VIIRS LSA, MODIS albedo product, and albedo retrieved from Landsat Enhanced Thematic Mapper Plus (ETM+) and Operational Land Imager (OLI) data. Section 2 gives a detailed description of the data sets used for the validation, including field measurement data and three different satellite data. Section 3 performs a detailed analysis on the validation results. Section 4 summarizes major findings and also states the limitations and problems in the current product.

\section{Data}

\subsection{Ground Measurements}

In this study, ground measured albedo was collected over 23 sites for the whole years 2012 and 2013 to conduct a direct comparison among various LSA products or retrievals with field measurements. To demonstrate the quality of these products over different land surfaces, these sites are selected from different networks, including SURFRAD, Ameri-Flux, BSRN, and GC-Net, covering various surface types such as vegetation, forest, desert, and snow. Table 1 summarizes the details of sites used for validation in this study.

Table 1. List of ground sites: networks, site names, geolocations, and surface types.

\begin{tabular}{|c|c|c|c|c|}
\hline Networks & Site & Latitude & Longitude & Land Surface Type \\
\hline \multirow{7}{*}{ SURFRAD } & Bondville & 40.05 & -88.37 & Cropland \\
\hline & Sioux Falls & 43.73 & -96.62 & Cropland \\
\hline & Table Mountain & 40.12 & -105.23 & Forest \\
\hline & Desert Rock & 36.62 & -116.01 & Desert \\
\hline & Boulder & 48.30 & -105.10 & Grassland \\
\hline & Penn State & 40.72 & -77.93 & Grassland \\
\hline & Goodwin Creek & 34.25 & -89.87 & Grassland \\
\hline \multirow{3}{*}{ BSRN } & Tateno & 36.05 & 140.12 & Grassland \\
\hline & Tiksi & 71.58 & 128.91 & Tundra \\
\hline & Toravere & 58.25 & 26.46 & Savannas \\
\hline \multirow{3}{*}{ Ameri-Flux } & USDia & 37.67 & -121.53 & Grassland \\
\hline & USFR3 & 29.94 & -97.99 & Grassland \\
\hline & USWcr & 45.80 & -90.07 & Grassland \\
\hline \multirow{10}{*}{ GC-Net } & GITS & 77.13 & -61.04 & Snow \\
\hline & Humboldt & 78.52 & -56.83 & Snow \\
\hline & Summit & 72.57 & -38.50 & Snow \\
\hline & Tunu-N & 78.01 & -33.98 & Snow \\
\hline & DYE-2 & 66.48 & -46.28 & Snow \\
\hline & Saddle & 65.99 & -44.50 & Snow \\
\hline & South-Dome & 63.14 & -44.81 & Snow \\
\hline & NASA-E & 75.00 & -29.99 & Snow \\
\hline & NASA-SE & 66.47 & -42.49 & Snow \\
\hline & NEEM & 77.50 & -50.87 & Snow \\
\hline
\end{tabular}

\subsection{VIIRS LSA EDR Product}

VIIRS LSA EDR is a granule-based product similar to the MODIS level 2 swath products. Seven VIIRS moderate resolution bands (M1, M4, M5, M7, M8, M10, and M11) are used to establish the relationship between the shortwave broadband albedo and the TOA reflectance [15]. This product provides instantaneous blue-sky albedo every day at the overpass time (13:30 local time) of the VIIRS sensor for all clear-sky, daytime, and land surface pixels with the spatial resolution of $750 \mathrm{~m}$ at nadir. 
Each pixel has been flagged either "definitely clear", "probably clear", or "probably cloudy" by the VIIRS Cloud Mask IP. VIIRS LSA EDR is available to download at the NOAA CLASS website [38]. In this study, considering that the operational LSA EDR product experienced several code changes and the data might not be consistent since its publication, the validation results given in Section 3 are based on the LSA data retrieved from our local infrastructure by employing improved BPSA on the original moderate resolution bands. Compared to the latest version of the operational product, our local computation in this study involved improved LUT for desert and snow surfaces. Upon the approval of the project management, such improvements will be imported into the next version of the operational EDR product. By matching the date and geolocation with ground measurement sites, VIIRS LSA data were also calculated for the 23 sites list in Table 1 covering the same time period.

\subsection{MODIS Albedo Product}

MODIS albedo and bidirectional reflectance distribution function (BRDF) products (MCD43A1 and MCD43A2) with 500-m spatial resolution covering the same time and same location are also collected. The MODIS blue-sky albedo is calculated as the weighted average of black-sky albedo and white-sky albedo. The weight is determined by the ratio of downward diffuse radiation, which is a function of solar zenith angle (SZA) and atmosphere optical depth (AOD) obtained through a simulation of atmospheric radiative transfer with MODTRAN 5. AOD information is obtained from MODIS daily AOD products (MOD08_D3). When no valid AOD retrieval is available, an AOD value of 0.2 is used [15]. Since MODIS BRDF is calculated from 16 days of data, the MODIS albedo used in this study is also a 16-day mean retrieval.

\subsection{Landsat-Retrieved Albedo}

Both VIIRS and MODIS data are moderate resolution product, which are not capable of manifesting the details and subtle changes of land variables, especially in heterogeneous areas. To investigate the influence of land heterogeneity and mixed pixel effect on the VIIRS albedo validation results, we also collected Landsat data (Landsat 7 ETM+ and Landsat 8 OLI, up to 3TB in total) over those 23 sites of the same period. With a high spatial resolution $(30 \mathrm{~m})$, Landsat-retrieved albedo is expected to function as a bridge between VIIRS LSA and the ground measurement, thereby helping in further understanding the main factor that leads to the biases of VIIRS LSA retrievals. The algorithm used to calculate the albedo from Landsat TOA observation in this study is similar to the one developed by [39].

\section{Result Analysis}

\subsection{VIIRS Validation Against Field Measurements}

Based on Table 1 and considering the properties of various land surfaces, we separated all sites into three categories: vegetated surface, desert, and snow. Based on this scheme, all 10 GC-Net sites located in Greenland are classified as snow sites; Desert Rock from SURFRAD is the only site that is considered desert surface; all other 12 sites are treated as vegetated surfaces, including cropland, grassland, forest, tundra, and savannas. For all the comparison results below, the absolute root mean square error (RMSE) and absolute bias will be used to measure the agreement between satellites retrievals and ground truth.

\subsubsection{Vegetated Surfaces}

As stated in our previous work [15], for vegetated surfaces, generic look-up-table (LUT) that uses all data in the BRDF database as the inputs of radiative transfer simulation is applied to calculate the LSA with observed TOA reflectance. Although no updates are made in generic LUT compared with that used in the [15], we conduct the ground validation over more vegetated sites in this study, attempting to lend more support to the results indicated in [15]. Figure 1 shows the comparison 
between VIIRS LSA and the ground truth albedo over four representative vegetated sites by combining the data of both years 2012 and 2013. Table 2 summarizes the comparison statistics, including bias and RMSE for all vegetated sites. Several findings can be made based on Figure 1 and Table 2. (1) Snow cover in the winter season significantly increase the surface albedo $(>0.4)$, leading to obvious contrast to snow free observations $(<0.25)$ and thereby showing two clusters on the scatter plots for some sites (Figure 1a,c,d); (2) For the sites free of snow over throughout the year like Goodwin Creek (Figure 1b), the VIIRS LSA retrieval is quite reliable with RMSE of lower than 0.035 and a slight negative bias of -0.020 , demonstrating the effectiveness of the generic LUT over dark vegetated surfaces; (3) For the sites covered with snow during the winter season like Table Mountain (Figure 1c), the VIIRS LSA retrieval is impacted by the inaccurate estimation of high albedo values, with RMSE and bias increased up to 0.056 and 0.024 , respectively, suggesting that the generic LUT might not be appropriate for bright snow-covered surface (see more details in Section 3.1.3); (4) If the snow-covered observations (albedo > 0.4) are excluded and only snow-free observations are considered, the RMSE and bias are significantly decreased to 0.028 and 0.012 , respectively, and similar changes are also found for the site Tiksi (Figure 1d); (5) For Bondville (Figure 1a) from the SURFRAD network, which is known as a heterogeneous site, both RMSE and bias are quite high (RMSE $=0.079$ ) even if only snow-free observations $(\mathrm{RMSE}=0.071$ ) are included. Albedo validation results over this site are always not quite good in many related researches, probably because of the bad quality of field measurements over this site rather than the LSA product or the retrieval algorithms; (6) The overall RMSE and bias over all the 12 vegetated sites are 0.050 and -0.010 , respectively, for all observations, and decreased to 0.033 and -0.007 , respectively, if snow-covered observations are excluded. Such a level of accuracy is lower than that obtained by using LUT with Lambertian $[14,23,25,28]$ surface assumption (RMSE $=0.056$, Bias $=-0.015$, not shown in Table 2), which agree with the results provided by [15]. Moreover, according to [24], who validated MODIS-retrieved albedo with six vegetated sites from SURFRAD, the RMSE and bias between MODIS albedo and ground truth were about 0.026 and -0.002 , respectively, for snow-free observations. Considering that MODIS albedo is 16-day mean data and errors might be mitigated during the composition, it is safe to say that the VIIRS LSA retrievals over vegetated sites are comparable to MODIS, both of which are reliable albedo estimations.

Table 2. Summary of ground validation results over 12 vegetated sites. Generic BRDF LUT is used to retrieve LSA over these sites. "Overall" displays the statistics by including all available observations, while "Snow-free" only considers those snow-free observations whose ground albedo measurements are below 0.4 .

\begin{tabular}{ccccc}
\hline \multirow{2}{*}{ Site } & \multicolumn{2}{c}{ Overall } & \multicolumn{2}{c}{ Snow-Free } \\
\cline { 2 - 5 } & RMSE & Bias & RMSE & Bias \\
\hline Bondville & 0.079 & -0.040 & 0.071 & -0.040 \\
Sioux Falls & 0.051 & 0.031 & 0.024 & 0.007 \\
Table Mountain & 0.056 & 0.024 & 0.028 & 0.012 \\
Boulder & 0.024 & -0.003 & 0.027 & 0.007 \\
Penn State & 0.068 & -0.041 & 0.042 & -0.028 \\
Goodwin Creek & 0.033 & -0.020 & 0.033 & -0.020 \\
Tateno & 0.046 & -0.003 & 0.046 & -0.003 \\
Tiksi & 0.042 & 0.010 & 0.040 & 0.016 \\
Toravere & 0.051 & 0.007 & 0.053 & 0.005 \\
USDia & 0.038 & 0.004 & 0.038 & 0.004 \\
USFR3 & 0.036 & 0.026 & 0.036 & 0.026 \\
USWcr & 0.050 & -0.005 & 0.050 & -0.005 \\
Overall & $\mathbf{0 . 0 5 0}$ & $-\mathbf{0 . 0 1 0}$ & $\mathbf{0 . 0 3 3}$ & $-\mathbf{0 . 0 0 7}$ \\
\hline
\end{tabular}




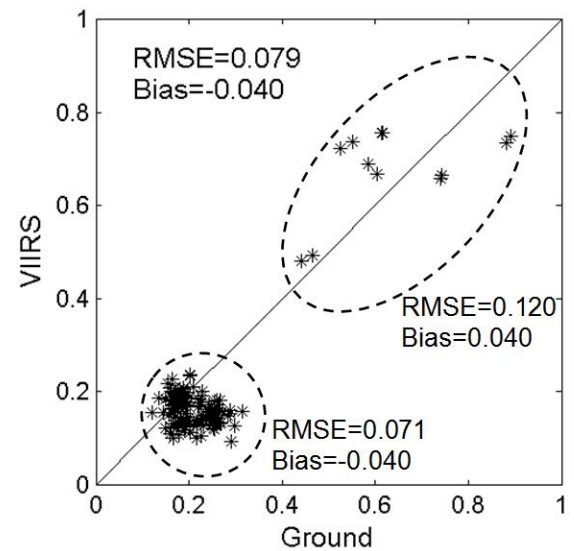

(a)

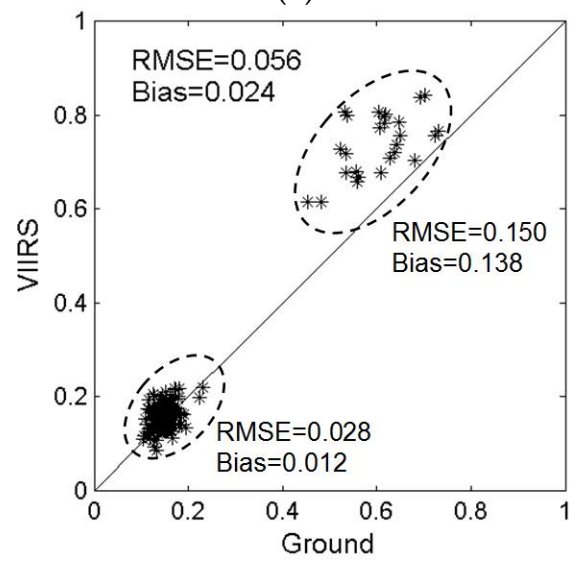

(c)

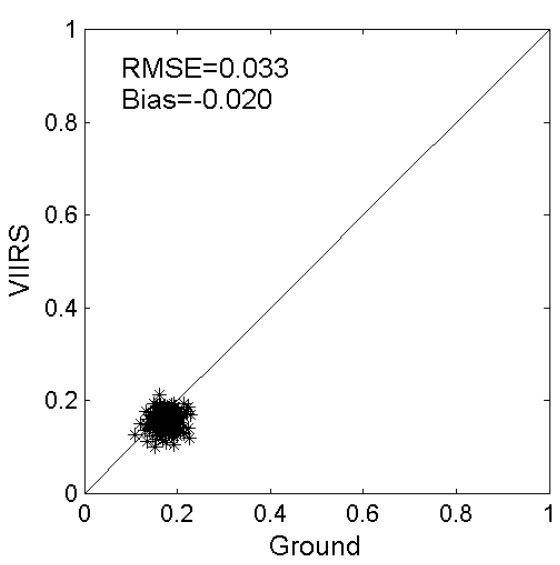

(b)

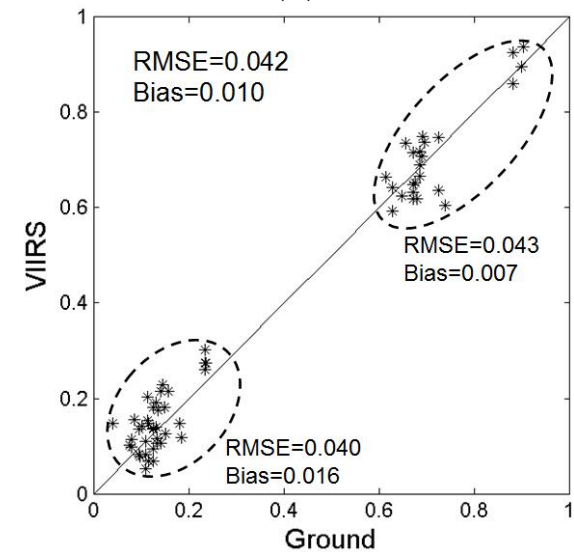

(d)

Figure 1. Comparison between VIIRS-retrieved albedo and ground truth over four vegetated sites for the years 2012 and 2013: (a) Bondville (Cropland); (b) Goodwin Creek (Grassland); (c) Table Mountain (Forest); and (d) Tiksi (Tundra). Albedo value beyond 0.4 is due to the snow cover on the sites during the winter season. Cloudy observations have been excluded by applying cloud masks.

\subsubsection{Desert}

For a desert surface, the current operational VIIRS LSA EDR is calculated by desert-specific LUT, which mainly uses the BRDF of bare soil in the simulation of atmospheric radiative transfer [15]. Validation against the field measurement over a desert site called Rock Desert from the SURFRAD network for the whole year 2013 (Figure 2a,c) shows that the current LSA EDR achieves an RMSE of 0.036 and a positive bias of 0.030 , both of which are much higher than those of MODIS albedo validation results reported by [24] $(\mathrm{RMSE}=0.027$, Bias $=-0.003)$. Considering that this site has a very stable surface condition, temporal composition (16-day mean) of MODIS albedo should not contribute so much to the difference in accuracy, suggesting that VIIRS albedo retrieval over the desert surface is not as accurate as expected. Thus, we revisited the radiative transfer simulation process and employed a stricter standard to select the training data that is specific for desert aerosol type. It should be noted that the updated desert LUT is only tested in our local environment rather than being incorporated into current operational VIIRS LSA EDR. Consequently, a new group of desert LUT was generated, which were employed to retrieve the LSA from the VIIRS TOA data provided by the NASA land subset in our local infrastructure. Figure $2 b$,d clearly demonstrate the improvement made in the retrieval accuracy over this site by using the updated desert LUT, with RMSE and bias reduced to 0.023 and 0.006, respectively, suggesting the potential of the updated desert LUT to improve the VIIRS albedo 
retrieval over desert site. Further validation will be performed using extensive desert sites in future works to comprehensively demonstrate the effectiveness of such improved desert LUT.

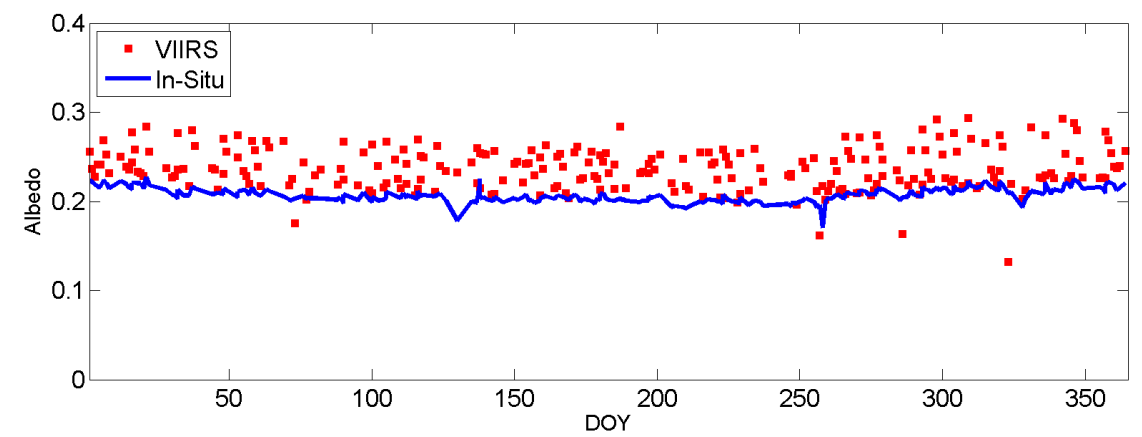

(a)

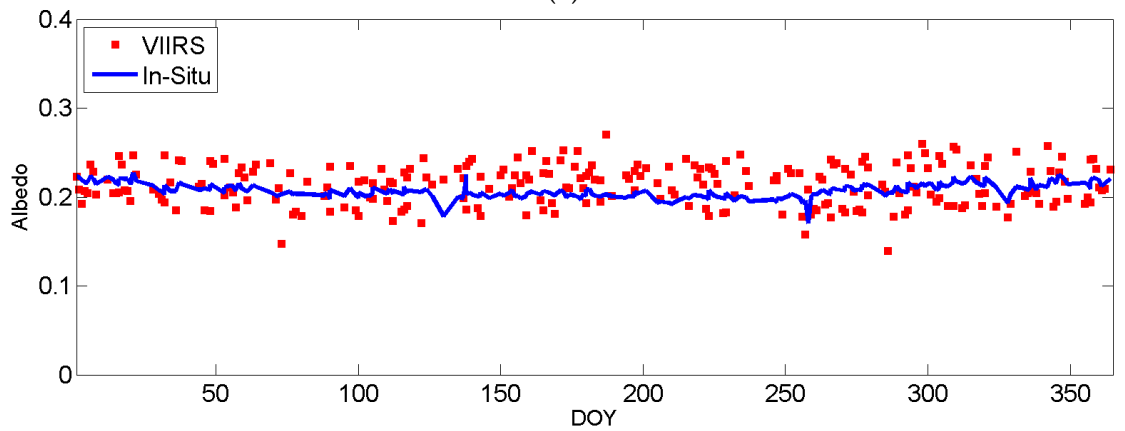

(b)

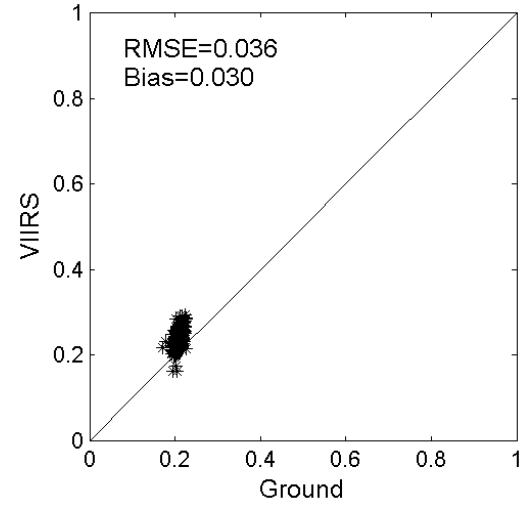

(c)

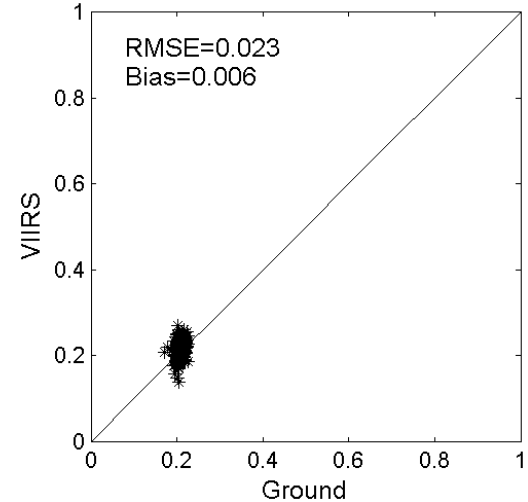

(d)

Figure 2. Validation results over a desert site (Rock Desert) for the year 2013. Time series of VIIRS-retrieved albedo using (a) current and (b) updated desert-specific LUT, respectively. Comparison results between ground truth and VIIRS-retrieved albedo using (c) current and (d) updated desert specific LUT, respectively.

\subsubsection{Snow}

For the snow surface, no snow-specific LUT is included in the current operational VIIRS LSA EDR. It simply uses the generic LUT to calculate LSA even if the surface is covered by snow, and no ground validation was performed over snow-covered sites by [15]. In this study, we collected the field measurement data over 10 snow sites from the GC-Net network for the year 2013 and extracted the corresponding VIIRS LSA EDR to perform accuracy assessment and related algorithm improvements. The data used for the comparison are only between May and October (i.e., DOY 121-304), because those snow sites are located in Greenland where the winter season (November to April) is very long and almost no field data are available during this period. 
As results, Figure 3 shows the comparison results over one of the GC-Net sites named Saddle. It can be seen that the retrieval accuracy of the generic LUT case (Figure 3b) is quite low, with the RMSE and bias of up to 0.092 and -0.032 , respectively. To achieve a better estimation, similar to the approach for constructing desert LUT, we also developed a group of snow-specific LUT by only using the BRDF of snow surface in the simulation of atmospheric radiative transfer. As expected, the LSA-retrieval accuracy was obviously improved by employing such snow-specific LUT on VIIRS TOA data provided by NOAA CLASS SDR, with RMSE and bias reduced to 0.073 and -0.005 , respectively (Figure 3c). Combining all the 10 snow sites together, Figure 4b,c indicate a similar result, with snow LUT (RMSE $=0.082$, Bias $=-0.016)$ outperforming the generic LUT $($ RMSE $=0.093$, Bias $=-0.052$ ). Such an accuracy is slightly worse than the MODIS 16-day mean albedo validation results over snow-covered sites reported by [24] $(\mathrm{RMSE}=0.065$, Bias $=0.012)$. However, even by using snow-specific LUT, the LSA retrieval over the snow surface is still significantly inferior to that of vegetated and desert surfaces. This large error is most likely caused by the undetected cloud and cloud shadow, which are much more difficult to identify in snow-covered regions than others. In addition, we found that the LUT with a Lambertian assumption performs slightly better than that of snow LUT (Figure 4a, Table 3). To investigate the cause, we analyzed the relationship between the solar/viewing geometry and the absolute difference (AD) of the VIIRS-retrieved and field-measured albedo. In Figure 5, it shows that the AD has almost no correlation with the solar zenith angle (SZA) for the Lambertian LUT case, while it shows an obvious increasing trend against SZA for the snow-specific LUT case. Considering that SZA is relatively higher in Greenland from where the ground measurements were collected, this is a straightforward explanation of the difference between the results showed in Figure $4 a$,c, and also helps us understand the potential improvements in product accuracy enabling the application of threshold SZA for snow-covered surfaces to decide which kind of LUT should be used for albedo retrieval.

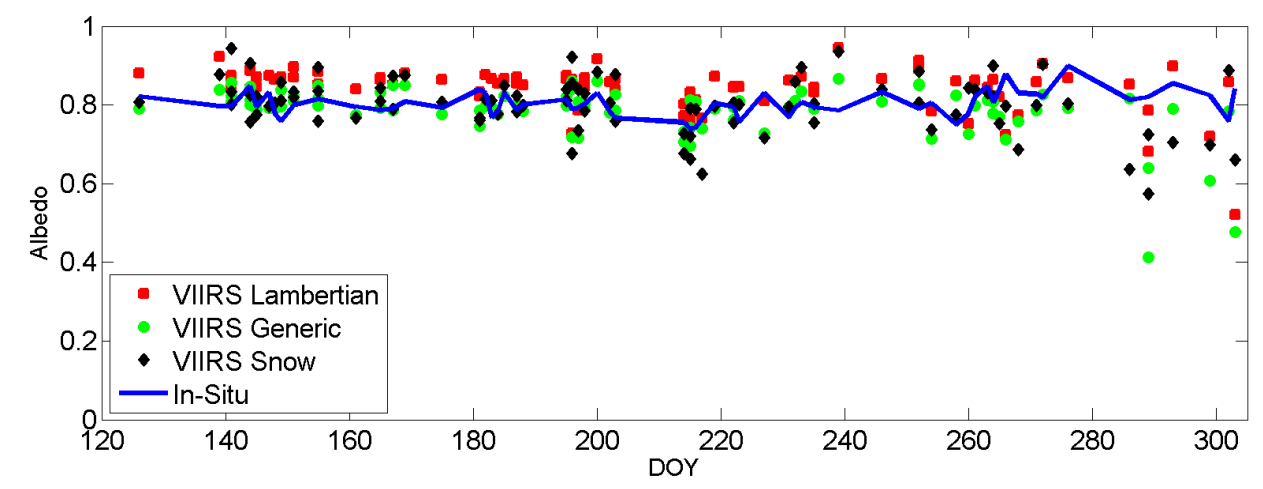

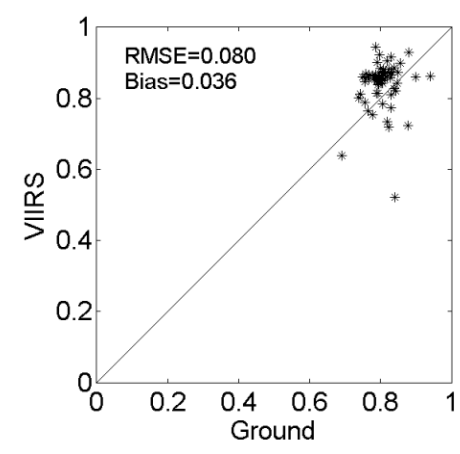

(b)

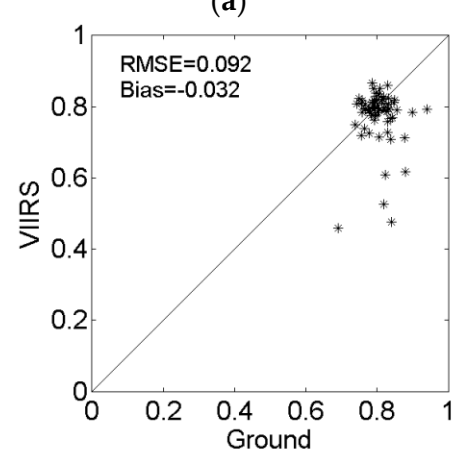

(c)

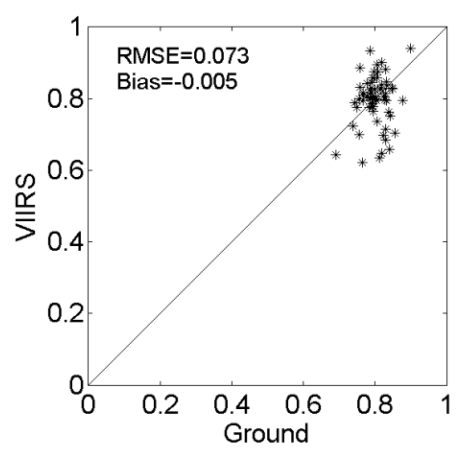

(d)

Figure 3. Validation results over a snow-covered site (Saddle) for the year 2013. (a) Time series of VIIRS-retrieved albedo using Lambertian LUT, generic BRDF LUT, and snow-specific BRDF LUT; Comparison results between ground truth and VIIRS-retrieved albedo using (b) Lambertian LUT; (c) generic BRDF LUT; and (d) snow-specific BRDF LUT, respectively. 


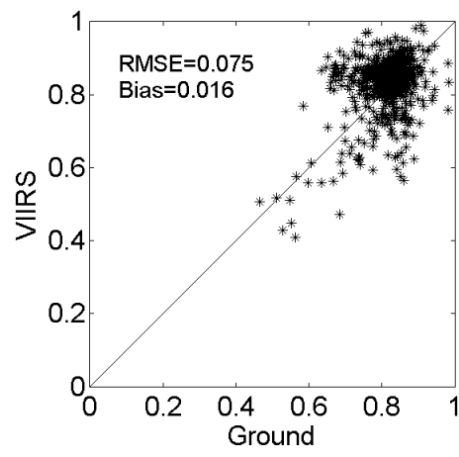

(a)

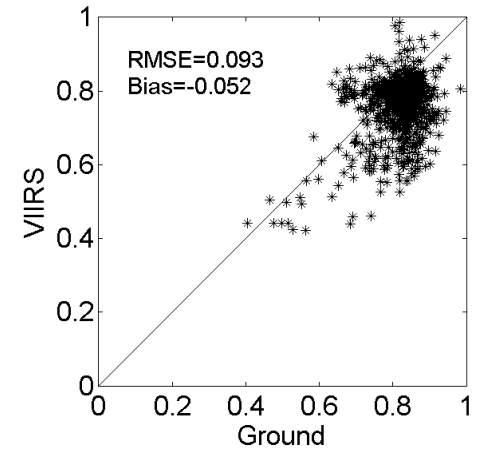

(b)

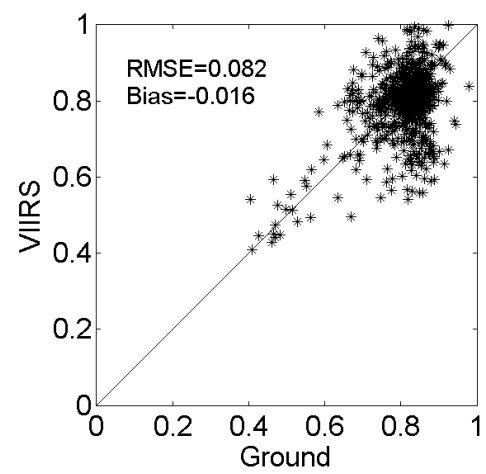

(c)

Figure 4. Comparison results over all snow-covered sites located in Greenland from the GC-Net network for the year 2013. VIIRS albedo is retrieved using (a) Lambertian LUT; (b) generic BRDF LUT; and (c) snow-specific BRDF LUT, respectively.

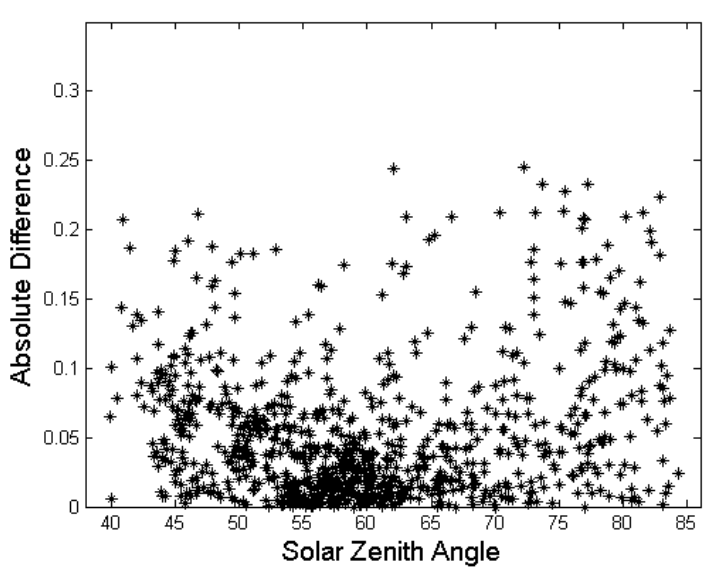

(a)

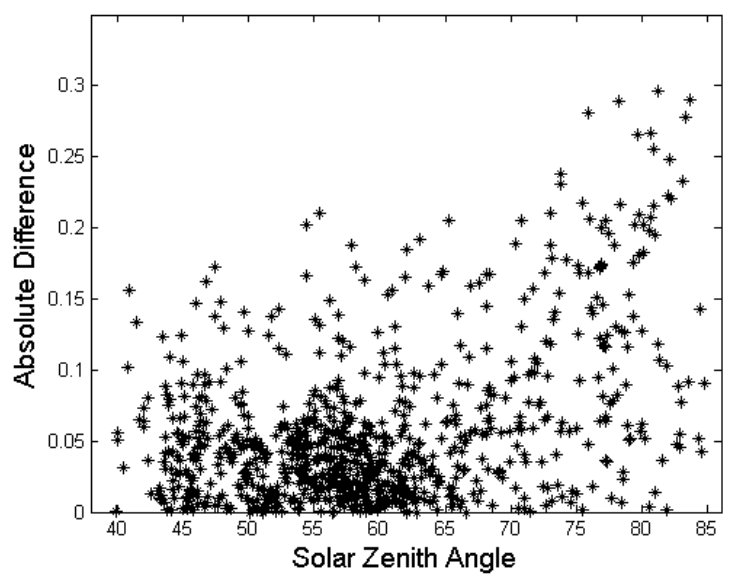

(b)

Figure 5. Relationship between the solar zenith angle and the absolute difference of VIIRS albedo retrieval ( l estimation-ground truth | ) for (a) Lambertian LUT; and (b) snow-specific BRDF LUT.

Table 3. Summary of ground validation results over 10 snow sites.

\begin{tabular}{ccccccc}
\hline \multirow{2}{*}{ Site } & \multicolumn{2}{c}{ Lambertian LUT } & \multicolumn{2}{c}{ Generic LUT } & \multicolumn{2}{c}{ Snow LUT } \\
\cline { 2 - 7 } & RMSE & Bias & RMSE & Bias & RMSE & Bias \\
\hline GITS & 0.067 & 0.011 & 0.102 & -0.066 & 0.068 & -0.012 \\
Humboldt & 0.081 & -0.013 & 0.095 & -0.073 & 0.090 & -0.046 \\
Summit & 0.058 & 0.037 & 0.072 & -0.028 & 0.058 & -0.007 \\
Tunu-N & 0.050 & -0.017 & 0.087 & -0.072 & 0.090 & -0.057 \\
DYE-2 & 0.103 & 0.067 & 0.074 & 0.007 & 0.070 & 0.039 \\
Saddle & 0.080 & 0.036 & 0.092 & -0.032 & 0.073 & -0.005 \\
South-Dome & 0.143 & 0.106 & 0.096 & 0.053 & 0.096 & 0.057 \\
NASA-E & 0.065 & -0.011 & 0.090 & -0.060 & 0.083 & -0.037 \\
NASA-SE & 0.069 & 0.029 & 0.077 & -0.036 & 0.072 & -0.018 \\
NEEM & 0.059 & 0.006 & 0.084 & -0.056 & 0.068 & -0.040 \\
Overall & $\mathbf{0 . 0 7 7}$ & $\mathbf{0 . 0 0 6}$ & $\mathbf{0 . 0 9 3}$ & $-\mathbf{0 . 0 5 2}$ & $\mathbf{0 . 0 8 7}$ & $-\mathbf{0 . 0 2 4}$ \\
\hline
\end{tabular}

\subsection{VIIRS Validated against Landsat}

High-resolution Landsat data provide us an effective way to investigate the influence of the heterogeneous surface and the mixed pixel effect on the validation results of VIIRS LSA EDR against 
field measurement. Considering that the spatial resolution of Landsat data is $30 \mathrm{~m}$ and the temporal resolution is 16 day, we averaged VIIRS LSA data in a window size of 25 pixels $\times 25$ pixels and also matched the acquisition dates of the Landsat. In addition, to exclude the influence of the albedo diurnal change caused by the SZA variation, in-situ albedo measured at the exact acquisition time of satellite images (VIIRS and Landsat, respectively) are used to perform ground comparisons. For the vegetated site USDia and snow site Tunu-N (first and third rows in Figure 6, respectively), Landsat provides more accurate albedo estimations than VIIRS LSA, whereas it is opposite over the desert site Desert Rock (second row in Figure 6). From Figure 7, which shows the combined comparison results, we found that Landsat-retrieved albedo also outperforms VIIRS LSA in general. Furthermore, the agreement between VIIRS and Landsat (RMSE $=0.048)$ is worse than that between VIIRS and MODIS (RMSE $=0.045$ ) shown in Section 3.3, most likely because (1) the difference in spatial resolution between VIIRS and MODIS $(250 \mathrm{~m})$ is much smaller than that between VIIRS and Landsat $(720 \mathrm{~m})$; (2) the estimation errors are mitigated by 16-day average of MODIS albedo product; and (3) the image acquisition time differs between Landsat and VIIRS, whereas the VIIRS-MODIS comparison used 16-day mean data which significantly mitigated the influence of acquisition differences. Similar to Section 3.1.1, we also excluded snow-covered observations over non-GCNet sites, because although they are snow pixels, they are retrieved by generic BRDF LUT rather than by snow-specific LUT. Figure 8 shows the accuracy improvement with such a modification, and it could be concluded that the VIIRS LSA is comparable with high-resolution Landsat albedo with RMSE of lower than 0.04 and also that Landsat albedo affords reliable retrievals with RMSE of lower than 0.035. In addition, we recognized that the different scaling between VIIRS and Landsat data may contribute most to the disagreement between their albedo retrievals, and also that employing point spread function (SPF) $[40,41]$ during the albedo retrieval of higher-resolution data is a potential way to improve the intercomparison results in future work.
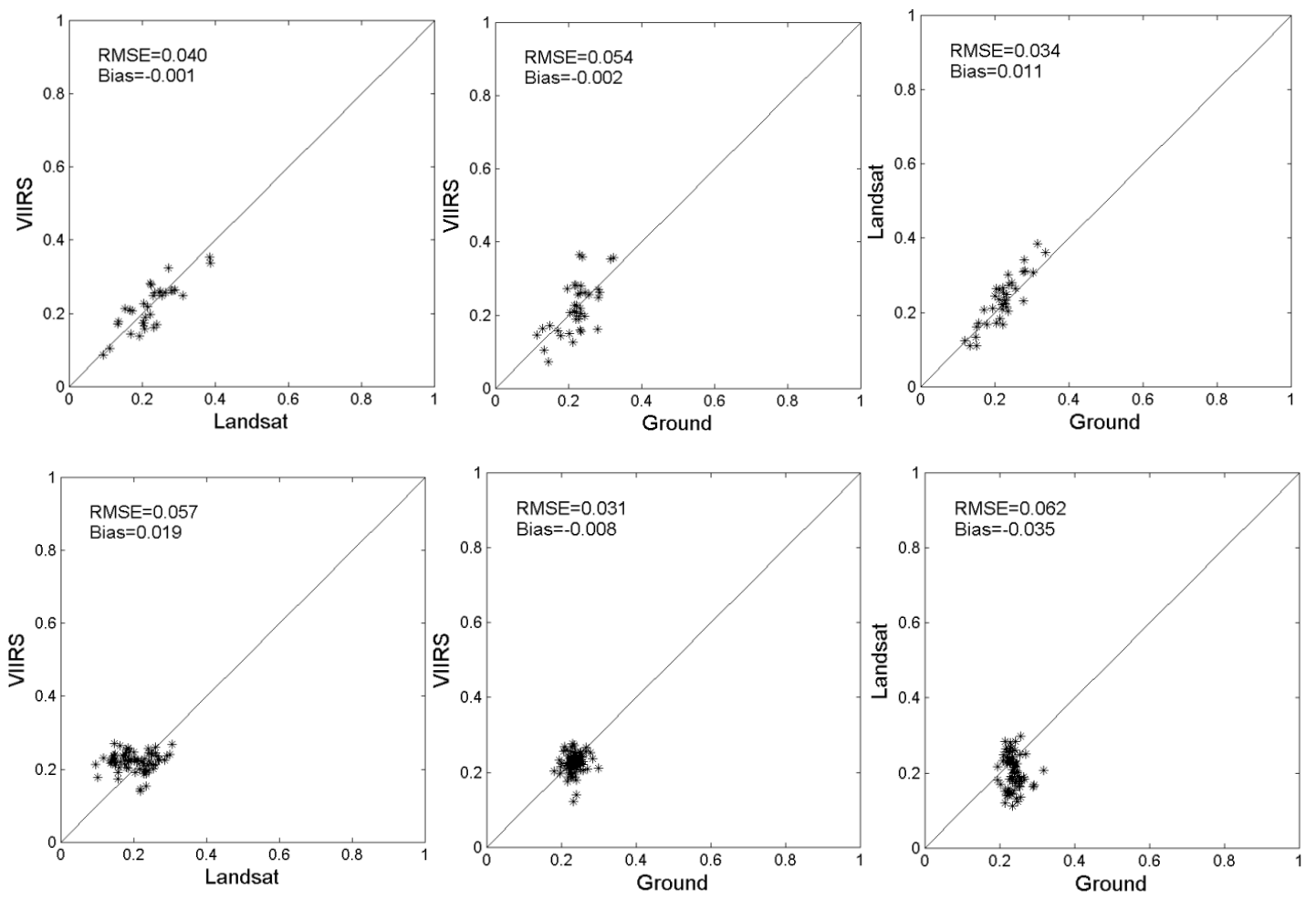

Figure 6. Cont. 

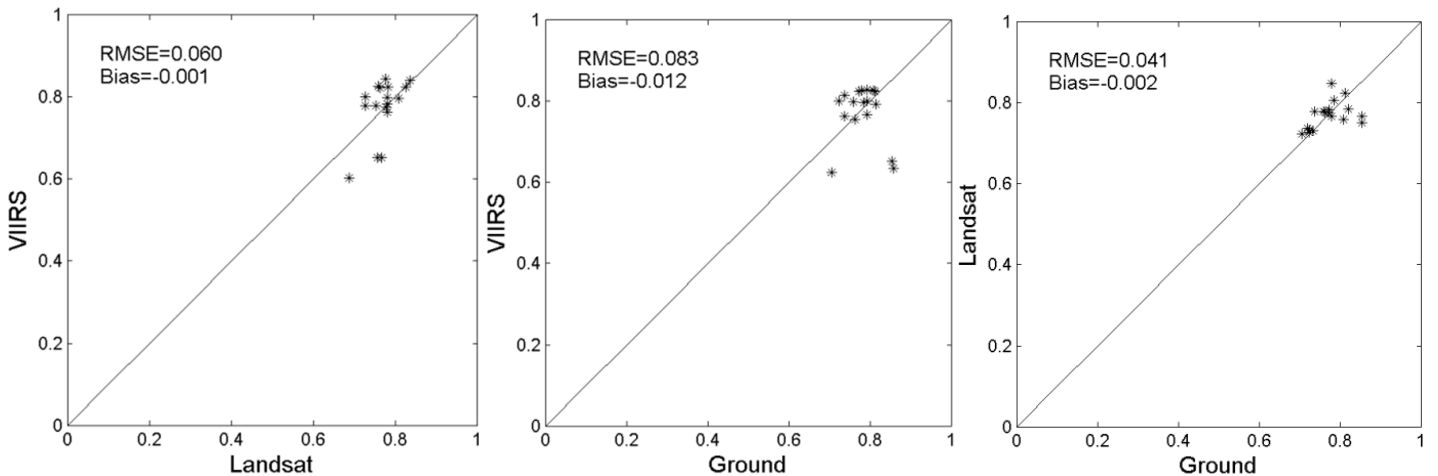

Figure 6. Intercomparison results (first column) between VIIRS LSA and Landsat-retrieved albedo for the years 2012 and 2013. Three individual sites (USWcr: first row; Desert Rock: second row; DYE-2: third row) covered by different land types are shown. In addition, comparisons with field measurements are also provided for the both products/retrievals in the second and third columns, respectively.

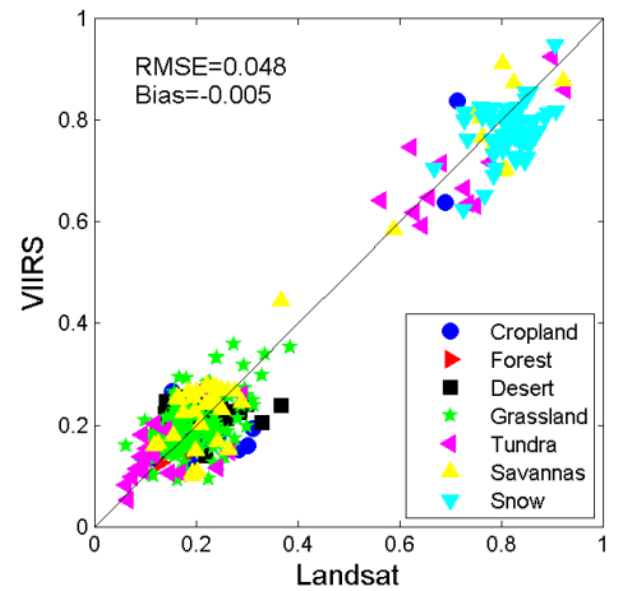

(a)

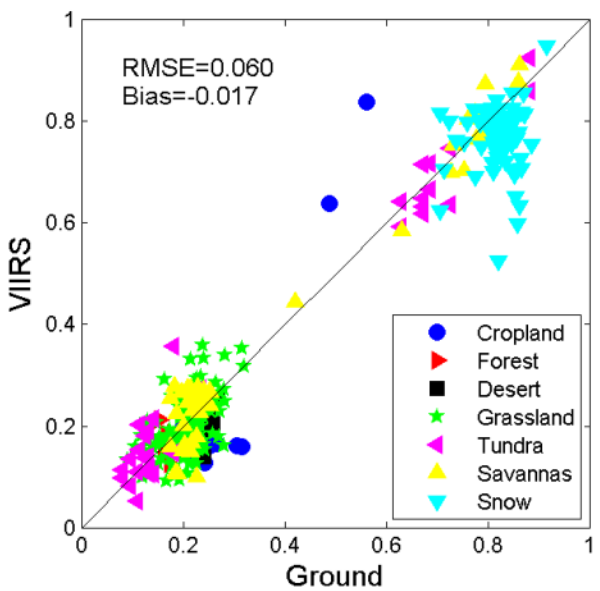

(b)

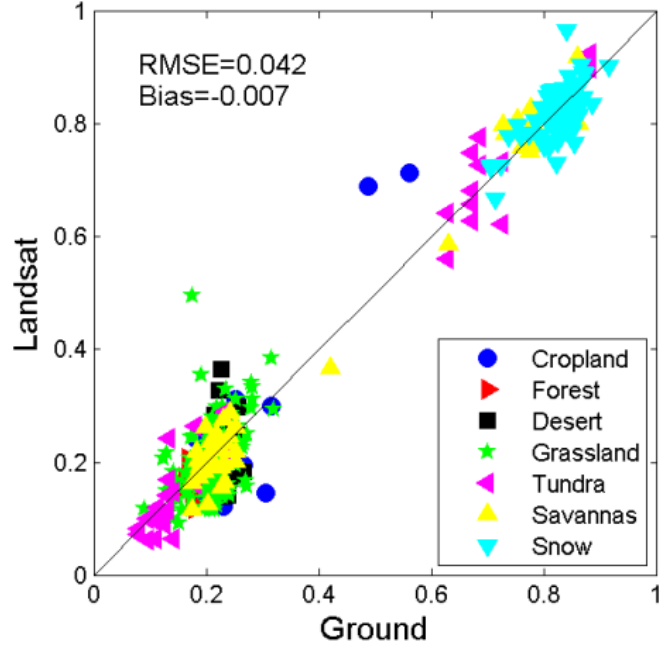

(c)

Figure 7. Inter-comparison results between VIIRS LSA and Landsat retrieved albedo over all sites listed in Table 1. (a) VIIRS validated against Landsat; (b) VIIRS validated against ground truth; (c) Landsat validated against ground truth. 


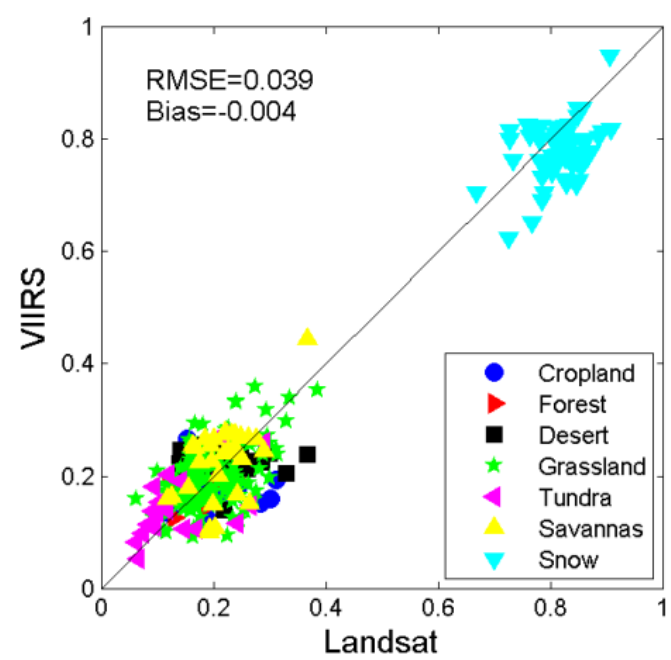

(a)

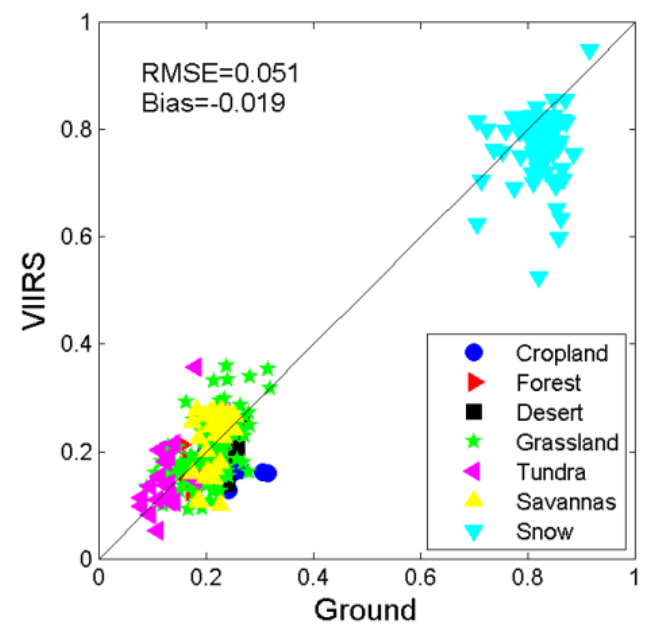

(b)

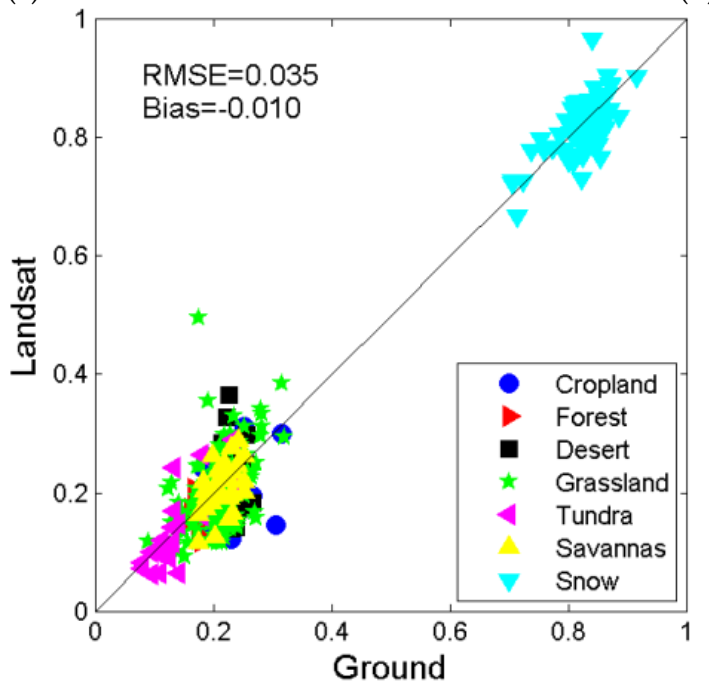

(c)

Figure 8. Modified inter-comparison results by excluding snow-covered observations over all non-GCNet sites on the basis of Figure 7. (a) VIIRS validated against Landsat; (b) VIIRS validated against ground truth; (c) Landsat validated against ground truth.

\subsection{VIIRS Validated against MODIS}

As a successor of MODIS, it is necessary to carry out a comparison between VIIRS LSA EDR and MODIS albedo product. Since the MODIS albedo is 16-day mean retrieval, 16-day data from VIIRS LSA are firstly averaged to obtain the mean albedo with an interval of 8 days, corresponding to the temporal step of the MODIS albedo. As shown in Figure 9, because of the mitigation of temporal variation and system noise by 16-day composition, all the comparison results are much better than those of simultaneous observations listed before. In detail, for all the three individual sites (i.e., Goodwin Creek, Desert Rock, and Saddle), VIIRS LSA agree quite well with the MODIS albedo product, with RMSE of lower than 0.05 at the snow site Saddle, and the other two vegetated and desert sites achieve an even much higher accuracy (with RMSE of lower than 0.02). In addition, both VIIRS LSA and MODIS products also show high agreements with field measurements, indicating the high data quality of these two products. Combining all sites together and separating into the abovementioned three surface types (Figure 9), we obtained more middle-range (0.35-0.65) observations for seasonal snow, and the LSA retrieval accuracy could be tested across the whole logical domain. As expected, it can be seen 
that VIIRS LSA is still comparable with the MODIS albedo product, with RMSE of lower than 0.05 and bias of lower than 0.025 .
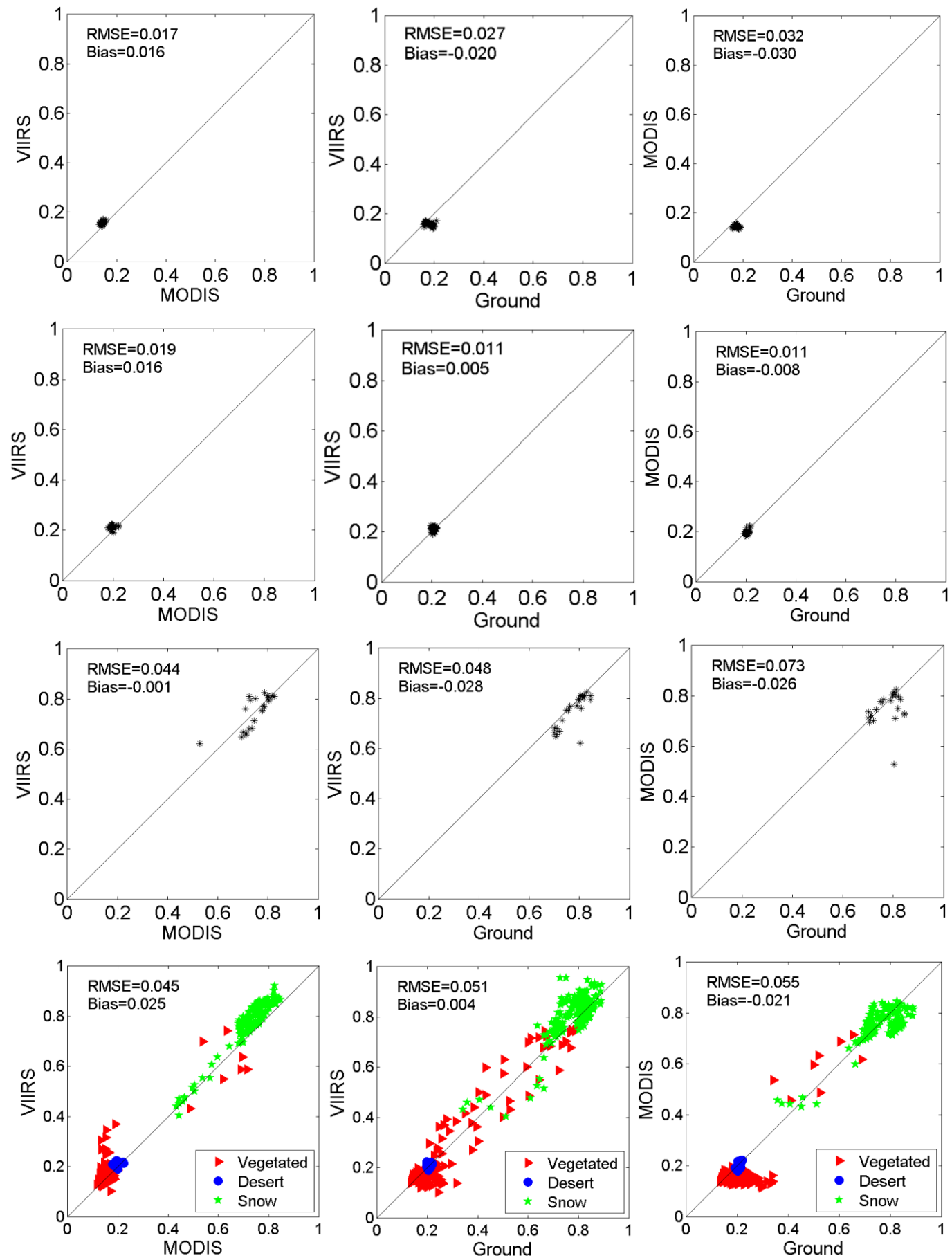

Figure 9. Intercomparison results (first column) between VIIRS LSA EDR and MODIS albedo product for the year 2013. Three individual sites (Goodwin Creek: first row; Desert Rock: second row; Saddle: third row) covered by different land types are shown, as well as the results of combining all the sites listed in Table 1 (fourth row). In addition, comparisons with field measurements are also provided for both the products in the second and third columns, respectively. 


\section{Summary}

Suomi NPP VIIRS LSA EDR has been a routinely operational product since the beginning of 2012. It currently employs BPSA as a unique algorithm to directly estimate LSA from VIIRS TOA reflectance. This paper summarizes the recent refinement of the BPSA LUT coefficients for desert and snow-covered surface and the comprehensive validation results of VIIRS LSA EDR. The major findings are summarized below.

(1) The updated desert LUT captures better albedo over a desert site than the original LUT upon the test results in the local environment, suggesting the potential of such updated LUT to the improve the VIIRS LSA product accuracy. Further validations with extensive desert sites are needed to comprehensively demonstrate the effectiveness of the new desert LUT. In addition, the newly developed snow-specific LUT also improves the accuracy of VIIRS LSA estimation over snow surfaces, thereby improving the overall accuracy over all validation sites.

(2) For snow-covered sites from the GC-Net network, LSA retrieved using both Lambertian-based LUT and snow-specific BRDF LUT perform much better than that obtained using generic BRDF LUT. In addition, Lambertian LUT generates a slightly higher accuracy than that of snow-specific LUT, owing to the different sensitivity of albedo estimation biases to the SZA between the two LUTs. Further investigation might be needed to identify a threshold of SZA to determine the most appropriate LUT for snow-covered surface in high-latitude areas.

(3) By validating against Landsat-retrieved albedo, it is found that VIIRS LSA is also comparable to high-resolution albedo retrieval (RMSE $<0.04$ ), although Landsat albedo has slightly better ground validation results than that of VIIRS, which is probably attributed to the fact that the high-resolution Landsat data is nearly free from the impact of heterogeneous surface and mixed pixel effect. Point spread function will be implemented to mitigate such discrepancies in future works.

(4) VIIRS LSA retrievals agree well with the MODIS albedo product over all kinds of surfaces, including vegetated, desert, and snow surfaces, with the overall RMSE of lower than 0.05 and overall bias of lower than 0.025 . As the successor of MODIS, it is demonstrated that VIIRS is capable of producing LSA product, whose accuracy is comparable to MODIS.

Acknowledgments: We thank the SURFRAD, BSRN, GC-Net, and Ameri-flux network for providing the field measurements of flux variables. This study is supported from the JPSS ground segment Data and Product Algorithm team.

Author Contributions: Yuan Zhou conducted the primary data collection and processing and result analysis, as well as composing the manuscript. Dongdong Wang contributed to the algorithm development, validation experiment design, and significant editing to the manuscript. Shunlin Liang and Yunyue Yu gave important comments and suggestions that improved the manuscript in each round of review. Tao He is the designer of the algorithm for retrieving land surface albedo using Landsat data.

Conflicts of Interest: The authors declare no conflict of interest.

\section{References}

1. Liang, S. Quantitative Remote Sensing of Land Surfaces; Wiley: Hoboken, NJ, USA, 2004.

2. Dickinson, R.E. Land surface processes and climate-Surface albedos and energy balance. Adv. Geophys. 1983, 25, 305-353.

3. Chapin, F.S.; Randerson, J.T.; McGuire, A.D.; Foley, J.A.; Field, C.B. Changing feedbacks in the climate-Biosphere system. Front. Ecol. Environ. 2008, 6, 313-320. [CrossRef]

4. Bonan, G.B. Forests and climate change: Forcings, feedbacks, and the climate benefits of forests. Science 2008, 320, 1444-1449. [CrossRef] [PubMed]

5. Sellers, P.J.; Hall, F.G.; Kelly, R.D.; Black, A.; Baldocchi, D.; Berry, J.; Ryan, M.; Ranson, K.J.; Crill, P.M.; Lettenmaier, D.P.; et al. BOREAS in 1997: Experiment overview, scientific results, and future directions. J. Geophys. Res. 1997, 102, 28731. 
6. Ollinger, S.V.; Richardson, A.D.; Martin, M.E.; Hollinger, D.Y.; Frolking, S.E.; Reich, P.B.; Plourde, L.C.; Katul, G.G.; Munger, J.W.; Oren, R.; et al. Canopy nitrogen, carbon assimilation, and albedo in temperate and boreal forests: Functional relations and potential climate feedbacks. Proc. Natl. Acad. Sci. USA 2008, 105, 19336-19341. [PubMed]

7. Lawrence, D.M.; Slingo, J.M. An annual cycle of vegetation in a GCM. Part II: Global impacts on climate and hydrology. Clim. Dyn. 2004, 22, 107-122.

8. Cescatti, A.; Marcolla, B.; Santhana Vannan, S.K.; Pan, J.Y.; Román, M.O.; Yang, X.; Ciais, P.; Cook, R.B.; Law, B.E.; Matteucci, G.; et al. Intercomparison of MODIS albedo retrievals and in situ measurements across the global FLUXNET network. Remote Sens. Environ. 2012, 121, 323-334.

9. Chapin, F.S.; Sturm, M.; Serreze, M.C.; McFadden, J.P.; Key, J.R.; Lloyd, A.H.; McGuire, A.D.; Rupp, T.S.; Lynch, A.H.; Schimel, J.P.; et al. Role of land-surface changes in arctic summer warming. Science 2005, 310, 657-660. [PubMed]

10. Rotenberg, E.; Yakir, D. Contribution of semi-arid forests to the climate system. Science 2010, 327, 451-454. [CrossRef] [PubMed]

11. Bird, D.N.; Kunda, M.; Mayer, A.; Schlamadinger, B.; Canella, L.; Johnston, M. Incorporating changes in albedo in estimating the climate mitigation benefits of land use change projects. Biogeosci. Discuss. 2008, 5, 1511-1543. [CrossRef]

12. Betts, R.A. Offset of the potential carbon sink from boreal forestation by decreases in surface albedo. Nature 2000, 408, 187-190. [CrossRef] [PubMed]

13. Anderson, R.G.; Canadell, J.G.; Randerson, J.T.; Jackson, R.B.; Hungate, B.A.; Baldocchi, D.D.; Ban-Weiss, G.A.; Bonan, G.B.; Caldeira, K.; Cao, L.; et al. Biophysical considerations in forestry for climate protection. Front. Ecol. Environ. 2011, 9, 174-182.

14. Liang, S. A direct algorithm for estimating land surface broadband albedos from MODIS imagery. IEEE Trans. Geosci. Remote Sens. 2003, 41, 136-145. [CrossRef]

15. Wang, D.; Liang, S.; He, T.; Yu, Y. Direct estimation of land surface albedo from VIIRS data: Algorithm improvement and preliminary validation. J. Geophys. Res. Atmos. 2013, 118, 12,577. [CrossRef]

16. Raschke, E.; Vonder Haar, T.H.; Bandeen, W.R.; Pasternak, M. The annual radiation balance of the earth-atmosphere system during 1969-1970 from Nimbus 3 measurements. J. Atmos. Sci. 1973, 30, 341-364. [CrossRef]

17. Li, Z.; Garand, L. Estimation of surface albedo from space: A parameterization for global application. J. Geophys. Res. 1994, 99, 8335. [CrossRef]

18. Csiszar, I.; Gutman, G. Mapping global land surface albedo from NOAA AVHRR. J. Geophys. Res. 1999, 104, 6215. [CrossRef]

19. Schaaf, C.B.; Gao, F.; Strahler, A.H.; Lucht, W.; Li, X.; Tsang, T.; Strugnell, N.C.; Zhang, X.; Jin, Y.; Muller, J.-P.; et al. First operational BRDF, albedo nadir reflectance products from MODIS. Remote Sens. Environ. 2002, 83, 135-148.

20. Salomonson, V.V.; Barnes, W.L.; Maymon, P.W.; Montgomery, H.E.; Ostrow, H. MODIS: Advanced facility instrument for studies of the earth as a system. IEEE Trans. Geosci. Remote Sens. 1989, 27, 145-153. [CrossRef]

21. Lucht, W.; Schaaf, C.B.; Strahler, A.H. An algorithm for the retrieval of albedo from space using semiempirical BRDF models. IEEE Trans. Geosci. Remote Sens. 2000, 38, 977-998. [CrossRef]

22. Wang, D.; Liang, S.; He, T.; Yu, Y.; Schaaf, C.; Wang, Z. Estimating daily mean land surface albedo from MODIS data. J. Geophys. Res. Atmos. 2015, 120, 4825-4841. [CrossRef]

23. Qu, Y.; Liu, Q.; Liang, S.; Wang, L.; Liu, N.; Liu, S. Direct-estimation algorithm for mapping daily land-surface broadband albedo from MODIS data. IEEE Trans. Geosci. Remote Sens. 2014, 52, 907-919. [CrossRef]

24. He, T.; Liang, S.; Wang, D.; Wu, H.; Yu, Y.; Wang, J. Estimation of surface albedo and directional reflectance from Moderate Resolution Imaging Spectroradiometer (MODIS) observations. Remote Sens. Environ. 2012, 119, 286-300. [CrossRef]

25. Liang, S. Mapping daily snow/ice shortwave broadband albedo from Moderate Resolution Imaging Spectroradiometer (MODIS): The improved direct retrieval algorithm and validation with Greenland in situ measurement. J. Geophys. Res. 2005, 110. [CrossRef]

26. Gao, F. MODIS bidirectional reflectance distribution function and albedo Climate Modeling Grid products and the variability of albedo for major global vegetation types. J. Geophys. Res. 2005, 110. [CrossRef] 
27. Lucht, W.; Hyman, A.H.; Strahler, A.H.; Barnsley, M.J.; Hobson, P.; Muller, J.-P. A comparison of satellite-derived spectral albedos to ground-based broadband albedo measurements modeled to satellite spatial scale for a semidesert landscape. Remote Sens. Environ. 2000, 74, 85-98. [CrossRef]

28. Liang, S.; Strahler, A.H.; Walthall, C. Retrieval of land surface albedo from satellite observations: A simulation study. J. Appl. Meteor. 1999, 38, 712-725. [CrossRef]

29. Wang, Z.; Barlage, M.; Zeng, X.; Dickinson, R.; Schaaf, C. The solar zenith angle dependence of desert albedo. Geophys. Res. Lett. 2005, 32. [CrossRef]

30. Maignan, F.; Bréon, F.-M.; Lacaze, R. Bidirectional reflectance of Earth targets: Evaluation of analytical models using a large set of spaceborne measurements with emphasis on the hot spot. Remote Sens. Environ. 2004, 90, 210-220. [CrossRef]

31. Bicheron, P.; Leroy, M. Bidirectional reflectance distribution function signatures of major biomes observed from space. J. Geophys. Res. 2000, 105, 26669. [CrossRef]

32. Bacour, C.; Bréon, F.-M. Variability of biome reflectance directional signatures as seen by POLDER. Remote Sens. Environ. 2005, 98, 80-95. [CrossRef]

33. Muller, J.-P. Algorithm theoretical basis document ATBD 1:4: BRDF/ALBEDO RETRIEVAL. MERIS AlbedoMaps 2006, 1, 1-19.

34. Rutan, D.; Rose, F.; Roman, M.; Manalo-Smith, N.; Schaaf, C.; Charlock, T. Development and assessment of broadband surface albedo from Clouds and the Earth's Radiant Energy System Clouds and Radiation Swath data product. J. Geophys. Res. 2009, 114. [CrossRef]

35. Rutan, D.; Charlock, T.; Rose, F.; Kato, S.; Zentz, S.; Coleman, L. Global Surface Albedo from CERES/TERRA Surface and Atmospheric Radiation Budget (SARB) Data Product. In Proceedings of the 12th conference on atmospheric radiation (AMS), Madison, WI, USA, 10-14 July 2006.

36. He, T.; Liang, S.; Wang, D.; Shi, Q.; Tao, X. Estimation of high-resolution land surface shortwave albedo from AVIRIS data. IEEE J. Sel. Top. Appl. Earth Obs. Remote Sens. 2014, 7, 4919-4928. [CrossRef]

37. Hulley, G.C.; Hook, S.J. Intercomparison of versions 4, 4.1 and 5 of the MODIS land surface temperature and emissivity products and validation with laboratory measurements of sand samples from the Namib desert, Namibia. Remote Sens. Environ. 2009, 113, 1313-1318.

38. NOAA Comprehensive Large Array-data Stewardship System (CLASS). Available online: http:/ / www.nsof.class.gov/saa/products/welcome (accessed on 8 October 2014).

39. He, T.; Liang, S.; Wang, D.; Chen, X.; Song, D.-X.; Jiang, B. Land surface albedo estimation from Chinese HJ satellite data based on the direct estimation approach. Remote Sens. 2015, 7, 5495-5510. [CrossRef]

40. Mira, M.; Weiss, M.; Baret, F.; Courault, D.; Hagolle, O.; Gallego-Elvira, B.; Olioso, A. The MODIS (collection V006) BRDF/albedo product MCD43D: Temporal course evaluated over agricultural landscape. Remote Sens. Environ. 2015, 170, 216-228. [CrossRef]

41. Campagnolo, M.L.; Montano, E.L. Estimation of effective resolution for daily MODIS gridded surface reflectance products. IEEE Trans. Geosci. Remote Sens. 2014, 52, 5622-5632. [CrossRef] 